\title{
25+ Years of the Business Intelligence and Analytics Minitrack at HICSS: A Text Mining Analysis
}

\author{
Olivera Marjanovic \\ University of Sydney, Australia \\ olivera.marjanovic@sydney.edu.au
}

\author{
Barbara Dinter \\ Chemnitz University of Technology, Germany \\ barbara.dinter@wirtschaft.tu-chemnitz.de
}

\begin{abstract}
This research project is inspired by the occasion of the 50th anniversary of the Hawaii International Conferences on Systems Sciences (HICSS). As the current co-chairs of the longest-running minitrack on Business Intelligence (BI), Business Analytics (BA) and Big Data (as it is currently known) at HICSS, we report on its 27-year history of relevant and interesting research. Our insights into the key research themes and their progress over time were obtained through a semantic text mining of all research publications included in this minitrack since 1990. We also illustrate a practical method of using a sophisticated text-mining tool (Leximancer) so that it could be replicated by other researchers interested in content analysis methods in other research fields.
\end{abstract}

\section{Introduction}

A growing pressure to derive actionable intelligence from ever-increasing volumes of data continues to propel Business Intelligence (BI) and Business Analytics (BA) to the top of industry priority lists worldwide [15], [29]. This trend is further accelerated by an unprecedented interest in big data, often described by its $3 \mathrm{Vs}$ - Volume, Velocity (realtime generation and/or analysis of data) and Variety (structured and unstructured data from many sources).

Both BI and BA continue to be interpreted in very different and sometimes inconsistent ways. For example, in some industry circles the term BI has become synonymous with BA [18]. In others, BI is reduced to reporting tools. It is also used to describe technical infrastructure, including data warehousing (DW). At the same time, BA is increasingly used to denote advanced analytical tools, such as predictive analytics or data mining, see [18] and [38].

While definitions will continue to evolve, we use an "umbrella" term of Business Intelligence \& Analytics (BI\&A) to denote a whole spectrum of BI and BA applications, technical infrastructures (including DW) as well as corresponding organizational practices. Chen et al.'s [9] definition best reflects our all-encompassing term BI\&A, which according to the authors includes the underlying data processing and analytical technologies as well as "business-centric practices and methodologies" [9:1171].

Growing attention to BI\&A across all industry sectors has resulted in a significant increase in scholarly activity best demonstrated by a proliferation of academic articles in journals and conferences, especially those on big data. While BI\&A-related research is currently considered by numerous conferences, the Hawaii International Conference on Systems Sciences (HICSS) has been at forefront of BI\&A-related research for more than 25 years. Even more, based on bibliographic analysis of ten years of published research, Chen et al. [9] named HICSS as the premier conference for BI\&A research.

Furthermore, a more recent history of HICSS has seen a significant increase of minitracks and tracks investigating different aspects of big data as evidenced by their titles. However, in this paper we focus on the minitrack with the longest history of BI\&A-related research at HICSS, currently named "Organizational issues of Business Intelligence, Business Analytics and Big Data". The origins of this minitrack could be traced back to the Executive Support Systems minitrack started by Hugh Watson and Joseph Walls at HICSS-23 in 1990.

Inspired by the occasion of the $50^{\text {th }}$ anniversary of HICSS, in this paper we analyze the 27-year long history of this particular BI\&A minitrack, in order to identify its main research themes and reflect on their evolution over time, from the perspective of its current co-chairs/authors of this paper. Our insights about development of BI\&A-related research, as discussed in this long-standing minitrack, make an important research contribution to HICSS as well as BI\&A research in general.

We also illustrate a practical method of using a sophisticated BI\&A tool (i.e. a semantic text mining tool called Leximancer), for the analysis of content that 
in our case is also BI\&A-related. Other researchers, beyond $\mathrm{BI} \& \mathrm{~A}$, in particular those interested in text mining, could replicate the same method.

This paper is organized as follows. The next section gives an overview of the long tradition of BI\&A related research, setting the context for our work. Section 3 provides the necessary foundations of lexical analysis (text-mining) with the Leximancer tool, including basic terminology. This section also gives an overview of the related work on common approaches to using this tool, as reported in the multi-disciplinary literature. Section 4 describes our research method including data collection and analysis. Our research findings are presented in Section 5. Section 6 offers a brief discussion of the research method, our application of Leximancer as well as interesting opportunities for future work beyond this context. Finally Section 7 describes our conclusions and reflections on the research and practical contributions of this work beyond HICSS conference.

\section{BI\&A history}

A long history of BI\&A and its predecessors has resulted in extensive related research and a huge number of publications. Watson [37] provides a comprehensive overview of computer-based decision support concepts, starting in the 1960s. Similarly, Power [33] organizes the history of Decision Support Systems (DSS) into five broad categories, showing how DW, Executive Information Systems (EIS) and BI evolved in the late 1980s and early 1990s. Other overviews of DSS are offered in [4] and [20].

While we acknowledge their origins in DSS, in this paper we focus on the two major fields in BI\&A (i.e. $\mathrm{BI}$ and BA) as defined above. We also consider BI\&A to be a separate research stream from traditional DSS.

Turning our attention to BI\&A, we observe numerous contributions providing a "meta perspective" on the BI and BA topics, mainly in the form of literature reviews, research agendas, and conceptualizations of the fields. Based on extensive literature reviews, several authors focus on understanding, conceptualization and/or systematization of BI, see for example [6], [8], [24], [34] and [35]. Frequently, BI is differentiated into BIas-product, BI-as-a-process and BI-as-a-tool. Surprisingly few contributions offer a comprehensive research agenda for BI. Instead, they focus on selected, more-specific research challenges, such as those discussed in [6], [17], [30] and [37]. We also observe that BI meta papers tend to be past-oriented, often describing an evolution of BI-related research.
In contrast, meta papers about BA or big data (analytics) are rather future-oriented, thus setting future research agendas. Due to the emerging nature of big data, very few contributions provide extensive literature reviews and/or conceptualization of big data.

The agenda-setting nature of BA and big data meta papers is best demonstrated by the well-known BI\&A research framework by Chen et al's [9]. Similarly, Abbasi et al. [1] provide a comprehensive research agenda for big data according to the big data information value chain. Guided by a big data analytics framework, Phillips-Wren et al. [32] discuss future research opportunities in this field. Other notable BA meta papers that discuss research challenges include [19], [25], [31] and [38].

\section{Foundations of lexical analysis with Leximancer}

Leximancer is an advanced text mining software tool designed to analyze the frequency of cooccurrences of words within blocks of text, in order to produce a set of inter-related maps of derived semantic concepts and themes [27]. At its core, Leximancer applies complex statistical algorithms to very large volumes of unstructured textual data, in order to identify semantic concepts in data. Based on their derived semantic proximity, these concepts are grouped into clusters known as themes. The resulting themes are then visualized as the so-called concept maps represented by colored circles. The sizes and brightness of these circles correspond to the occurrences of identified themes within texts [27]. The resulting concept maps are used by Leximancer to establish the relational strength between different concepts so that it could be used by the researchers to interpret the strength of different associations. The software has been extensively evaluated for stability, reproducibility and correlative validity of underlying statistical algorithms [36].

In spite of very sophisticated analysis, it is important to point out that "meaning" is not automatically provided by the software, based on corelation and frequency of words contained in the text. Instead, the users who are domain experts are best suited to make sense of the visualized concepts in their own context in order to derive insights and comprehend what they mean. Leximancer supports this process of sense-making in two ways. In addition to user-friendly visualization of concepts and themes, the software also generates a thesaurus of identified concepts and their derived 'definitions'. For each identified concept or theme, the software enables the user to drill-down to the underlying 
paragraphs/sentences of raw (original) text from which these concepts were derived, in order to confirm or refine possible meaning.

Leximancer has been used for more than a decade by numerous of researchers in very diverse research fields, such as accounting [11], sports management [2], cross-cultural psychology [10], business ethics [28] and design science [22]. According to Indulska et al. [21] Leximancer is favored by many researchers doing data mining-based content analysis.

Finally, Leximancer has been used by other researchers to analyze relevant articles across different journals, for example in IS [7], [5], [21]. Leximancer is also used to map histories of research publications within a single journal or a conference, as intended by our research. Examples include the 40-year history of themes and concepts published by the Journal of Cross-Cultural Psychology [10], the 10-year history of the Sports Management International Journal [2] or the 22-year history of the Journal of Business-to-Business Marketing [39]. However, to the best of our knowledge, this type of content analysis has not been used to in the field of BI\&A and big data, to analyze histories of related conference (mini)tracks or journals. This is somewhat surprising given the fact that an advanced text mining tool such as Leximancer can be classified as a BI\&A tool and as such is our own "tool of the trade" within the BI\&A community. This particular observation has led to the main idea for our research, as described in this paper. The following section introduces our adopted research method.

\section{Research method}

\subsection{Data collection}

In this study we collected all articles published between 1990 and 2016 within the HICSS minitrack currently named 'Organizational aspects of Business Intelligence, Business Analytics and Big Data'. We traced its 27-years long history, taking into account its different names since its inception in 1990. All papers were sourced from the IEEE Explore and HICSS web sites. Some of the earlier proceedings (e.g. 1994) did not include published introductions to minitracks. In those cases, we cross-referenced the minitrack's list of papers (provided by IEEE Explore) with other databases including DBWorld and Google Scholar, to confirm the completeness of our data set. Table 1 depicts our resulting data set, including the minitrack's names (as they changed throughout the history) and the names of its co-chairs. This data set was used for our text-mining analysis as described in the next section.
Table 1. History of minitrack titles and co-chairs

\begin{tabular}{|c|c|c|}
\hline Year & Name & Chairs \\
\hline $\begin{array}{l}1990- \\
1996\end{array}$ & $\begin{array}{l}\text { Executive Information } \\
\text { Systems }\end{array}$ & HW, JW \\
\hline $\begin{array}{l}1997- \\
1998\end{array}$ & $\begin{array}{l}\text { Data Warehouses and } \\
\text { Information Delivery } \\
\text { Systems }\end{array}$ & HW, JW \\
\hline $\begin{array}{l}1999- \\
2003\end{array}$ & Data Warehousing & $\begin{array}{l}\text { BW, PG, } \\
\text { HW }\end{array}$ \\
\hline $\begin{array}{l}2004- \\
2008\end{array}$ & $\begin{array}{l}\text { Data Warehousing and } \\
\text { Business Intelligence }\end{array}$ & BW, HW \\
\hline 2009 & $\begin{array}{l}\text { Data Warehousing, } \\
\text { Business Intelligence and } \\
\text { Information Logistics }\end{array}$ & $\begin{array}{l}\text { HW, } \\
\text { RW, BW }\end{array}$ \\
\hline 2010 & $\begin{array}{l}\text { Data Warehousing, } \\
\text { Business Intelligence and } \\
\text { Information Logistics }\end{array}$ & $\begin{array}{l}\text { RW, } \\
\text { HW, BW }\end{array}$ \\
\hline 2011 & $\begin{array}{l}\text { Business Intelligence, Data } \\
\text { Warehousing and Process } \\
\text { Analytics }\end{array}$ & $\begin{array}{l}\text { RW, } \\
\text { OM, BW }\end{array}$ \\
\hline 2012 & $\begin{array}{l}\text { Business Analytics, } \\
\text { Business Intelligence and } \\
\text { Data Warehousing }\end{array}$ & $\begin{array}{l}\text { RW, } \\
\text { OM, BW }\end{array}$ \\
\hline 2013 & $\begin{array}{l}\text { Business Analytics, } \\
\text { Business Intelligence and } \\
\text { Big Data }\end{array}$ & $\begin{array}{l}\text { RW, } \\
\text { OM, BW }\end{array}$ \\
\hline 2014 & $\begin{array}{l}\text { Business Analytics, } \\
\text { Business Intelligence and } \\
\text { Big Data }\end{array}$ & $\begin{array}{l}\text { OM, TA, } \\
\text { BD }\end{array}$ \\
\hline 2015 & $\begin{array}{l}\text { Organizational Issues for } \\
\text { Business Intelligence, Busi- } \\
\text { ness Analytics and Big Data }\end{array}$ & $\begin{array}{l}\text { OM, TA, } \\
\text { BD }\end{array}$ \\
\hline 2016 & $\begin{array}{l}\text { Organizational Issues of } \\
\text { Business Intelligence, } \\
\text { Business Analytics and Big } \\
\text { Data }\end{array}$ & $\begin{array}{l}\text { OM, BD, } \\
\text { TA }\end{array}$ \\
\hline \multicolumn{3}{|c|}{ Minitrack co-chairs: } \\
\hline \multicolumn{3}{|c|}{$\begin{array}{l}\text { HW - Hugh Watson (1990-2010); } \\
\text { JW - Joseph Walls (1990-1998); } \\
\text { PG - Paul Gray (1999-2003); } \\
\text { BW - Barbara Wixom (1999-2013); } \\
\text { RW - Robert Winter (2009-2013); } \\
\text { OM - Olivera Marjanovic (2011-present); } \\
\text { BD - Barbara Dinter (2014-present); } \\
\text { TA - Thilini Ariyachandra (2014-present) }\end{array}$} \\
\hline
\end{tabular}




\subsection{Descriptive and lexical data analysis}

Our resulting data set included all peer-reviewed papers presented in this minitrack from 1990 to 2016. We excluded minitrack introductions and several panels held in the early years of this minitrack for two reasons. First, not all of them were published in the proceedings. Second, even when published and made available, they were not fully refereed publications.

All papers were then divided into four groups, corresponding to different historical phases of the minitrack, as determined by its changing titles and the observed shift in its main focus. As shown by Table 2, Group 1 included papers from 1990 to 1996 with the clear focus on "Executive Information Systems". Group 2 included papers from 1997 to 2003 with the brand new focus on data warehousing (DW). Group 3 included papers from 2004 to 2011. Although the topic of DW remained in the title for several more years, it was extended to include BI and, for two years, information logistics. Finally, Group 4 included papers from 2012 to 2016. This time period demonstrates the latest shift to BA (since 2012) and the most recent inclusion of Big Data (BD) from 2013 until today.

Table 2. Data Collection

\begin{tabular}{|c|l|l|c|}
\hline Group & $\begin{array}{l}\text { Time } \\
\text { Period }\end{array}$ & Focus & $\begin{array}{l}\text { No. of } \\
\text { papers }\end{array}$ \\
\hline $\mathbf{1}$ & $\begin{array}{l}1990- \\
1996\end{array}$ & $\begin{array}{l}\text { Executive Information } \\
\text { Systems }\end{array}$ & 38 \\
\hline $\mathbf{2}$ & $\begin{array}{l}1997- \\
2003\end{array}$ & $\begin{array}{l}\text { Data Warehousing } \\
\text { (DW) }\end{array}$ & 29 \\
\hline $\mathbf{3}$ & $\begin{array}{l}2004- \\
2011\end{array}$ & DW extended with BI & 36 \\
\hline $\mathbf{4}$ & $\begin{array}{l}2012- \\
2016\end{array}$ & $\begin{array}{l}\text { BI extended by BA } \\
\text { (from 2012) and Big } \\
\text { Data (from 2013) }\end{array}$ & 37 \\
\hline \multicolumn{2}{|r|}{ Total: } & $\mathbf{1 4 0}$ \\
\hline
\end{tabular}

Using the resulting data set of 140 papers we performed two types of analysis - descriptive and lexical. The main objective of descriptive analysis was to understand the widening global context of BI\&A research as discussed in this minitrack as well as its impact beyond the HICSS conference through citation analysis. The main objective of lexical analysis was to understand the changing nature of research discussed in this minitrack throughout its 27-year history.

We performed lexical analysis as follows. All collected research papers were uploaded into Leximancer and divided into four groups. Compared to other studies which use abstracts for Leximancer analysis, we decided to use complete (full) papers to increase richness of our data set.

The actual text mining process was guided by the authors and included several cyclical sense-making phases. In the first phase, we ran an initial overall analysis of all papers within each individual group. The main objective was to identify the most frequently occurring concepts while excluding the common stopwords such as 'and', 'or'. Concept maps were created for each group, enabling us to identify and remove additional stop-words such as 'pp.', 'hicss', 'proceedings' as they occurred in the headers/footers of all papers published by IEEE Explore. All resulting concepts were then analyzed to determine their relevance and semantic meaning, by examining the corresponding thesaurus (also compiled by Leximancer). Consequently some concepts were merged into more meaningful combined concepts (e.g. 'user' and 'users'). The emerging concepts were also examined by drilling down to the underlying extracts of texts from individual papers to better comprehend their meaning. For example, the concept named 'organization' by Leximancer was established to mean 'business' as in 'business perspective'. Each reflective cycle of 'words, insight, meaning' was followed by another cycle of Leximancer analysis, across all paper groups. To sustain the reliability of the results within each concept map, the same type of analysis was conducted across all groups. For example, the same stop-words were omitted from each concept map and analyzed in parallel across all four groups.

\section{Research findings}

\subsection{Descriptive analysis}

Figure 1 depicts the number of accepted papers per year. 63 papers have been submitted by authors from the US, 19 from Australia, 18 from Germany, 12 from Switzerland, 7 from Canada, 6 from UK, 5 from Finland and the rest from other countries. Figure 1 also illustrates how the number of papers for the three most active countries (US, Australia and Germany) has evolved over time.

While being very US-focused in its beginnings, the minitrack became more and more international over time. Eleven papers were presented by international author teams and five papers by practitioners.

We were also interested in the top contributors to the track - in terms of authors with most papers, institutions with most papers and the papers that have been most cited. For the latter we used the Google Scholar citation count. 


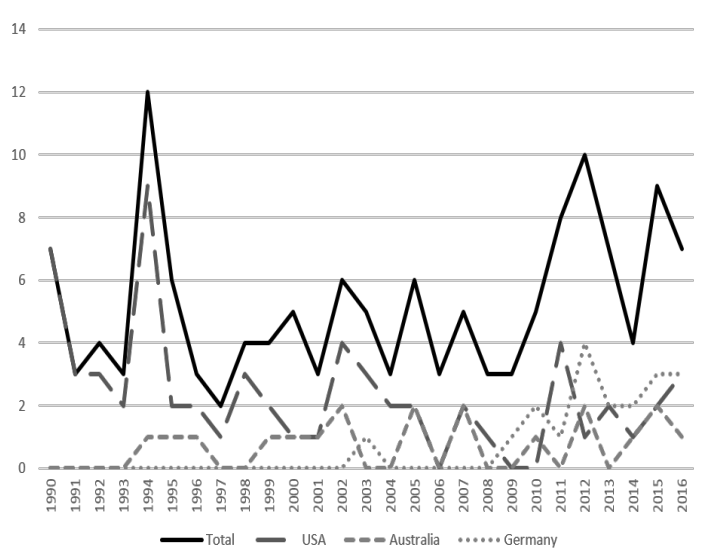

Figure 1. Number of papers per year

Table 3 includes the results for the Top 3 in each category. The right column includes the number of papers (authors / institutions) or of citations (papers).

Table 3. Top authors, affiliations and citations

\begin{tabular}{|c|l|c|}
\hline \multicolumn{3}{|l|}{ Most active authors } \\
\hline 1 & R. Winter, University of St.Gallen & 8 \\
\hline 2 & $\begin{array}{l}\text { M.K. Brohman, Queen's University; } \\
\text { S.A.Carlsson, Lund University; } \\
\text { M. Goul, Arizona State University; } \\
\text { D. Leidner, INSEAD; } \\
\text { O. Marjanovic, University of Sydney; } \\
\begin{array}{l}\text { C. Milligan, Sun Microsystems; } \\
\text { J.G. Walls, California State University; } \\
\text { F. Wortmann, University of St.Gallen }\end{array}\end{array}$ & \\
\hline Most active institutions & \\
\hline 1 & University of St.Gallen, Switzerland & 12 \\
\hline 2 & Arizona State University, USA & 8 \\
\hline 3 & $\begin{array}{l}\text { Curtin University, USA } \\
\text { University of Southern California, USA } \\
\text { University of Sydney }\end{array}$ & 5 \\
\hline Most cited papers & $\begin{array}{l}\text { M. Alavi, D. Leidner (1999). Knowledge } \\
\text { Management Systems: Emerging Views } \\
\text { and Practices from the Field }\end{array}$ & 368 \\
\hline 2 & $\begin{array}{l}\text { R. Winter, B. Strauch (2003). A Method } \\
\text { for Demand-driven Information } \\
\text { Requirements Analysis in Data } \\
\text { Warehousing Projects }\end{array}$ & 177 \\
\hline 3 & $\begin{array}{l}\text { O. Marjanovic (2007). The Next Stage } \\
\text { of Operational Business Intelligence: } \\
\text { Creating New Challenges for Business } \\
\text { Process Management }\end{array}$ & 61 \\
\hline
\end{tabular}

For the most active authors we found several authors at rank 2, and therefore we omitted rank 3 . We added the authors' affiliation of their most recent minitrack paper, respectively.

\subsection{Leximancer analysis results}

Figures 2 to 5 depict the concept maps of all four phases of this minitrack. They visualize the key themes and concepts identified in each of the four phases. As shown, Phase 1 demonstrates a very strong emphasis on EIS. This is very much expected given the title of the minitrack at the time. The largest circles also illustrate a strong focus on business/organizational aspects and applications of EIS rather than technology.

Phase 2 started with the new focus on "Data Warehousing" as reflected by the title. Our analysis confirms a very strong emphasis on data. Also, as shown the concept of 'warehouse' is linked to 'query' and 'database' indicating the focus on technical aspects. The authors also considered performance related issues, metrics and metadata. However, these concepts were clearly separated from technical issues.

Phase 3 offers a gradual shift from DW towards BI and BA. Even though the concept of DW remained in the title, it received less attention by the researchers, as shown by the concept map, with main emphasis being placed on BI.

Phase 4 represents the most recent phase of this minitrack, with the concept of big data being used for the last two years (2015 and 2016). Even though big data does appear as one of the themes identified by Leximancer, it is not the most prominent one.

Figure 6 offers further insights into the topic of big data and the ways it has been approached by the BI\&A researchers in this minitrack. For example, big data is linked to strategy, value and other organizational/business concepts, rather than technology infrastructure. This is very much expected given the main focus of the minitrack.

It is also interesting to observe a link to 'theory' indicating the researchers' objectives to develop a theory for this new phenomenon. However, the concept of 'big data' is still emerging, as indicated by the low values of all relevant indicators (such as "count" and "likelihood") for all related words (from 'strategy' to 'information') as shown on the right side of Figure 6. Also, big data is researched separately from the concept of $\mathrm{BI}$ as the likelihood of their co-occurrences is zero (as shown by Figure 6).

Table 4 offers a summary of the key themes and concepts found in each phase, along with our interpretation that has been informed by a more detailed "drill-down" analysis of the underlying (raw) text data. 


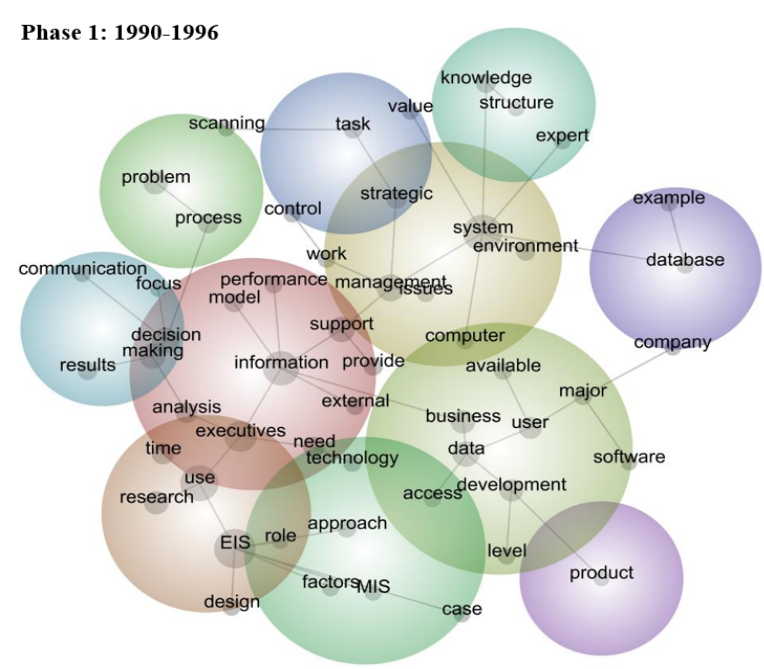

Figure 2. Leximancer concept map for Phase 1 Phase 2: 1997-2003

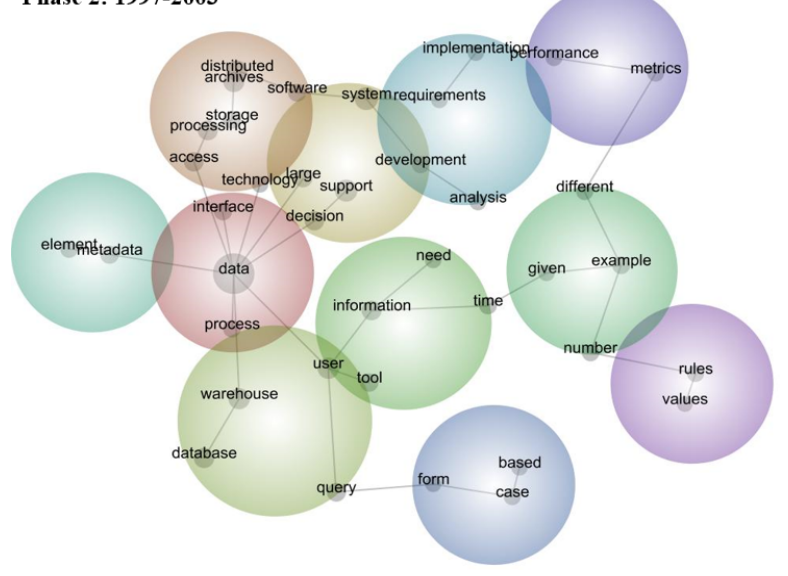

Figure 3. Leximancer concept map for Phase 2

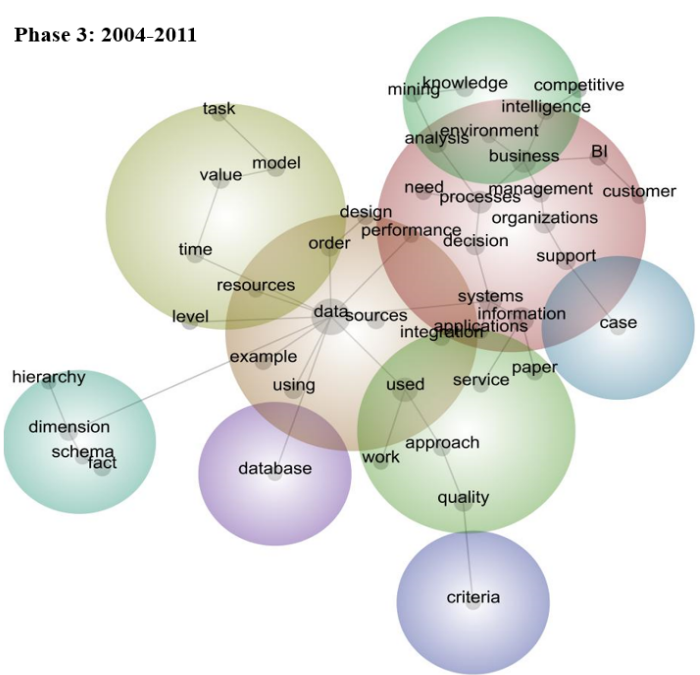

Figure 4. Leximancer concept map for Phase 3

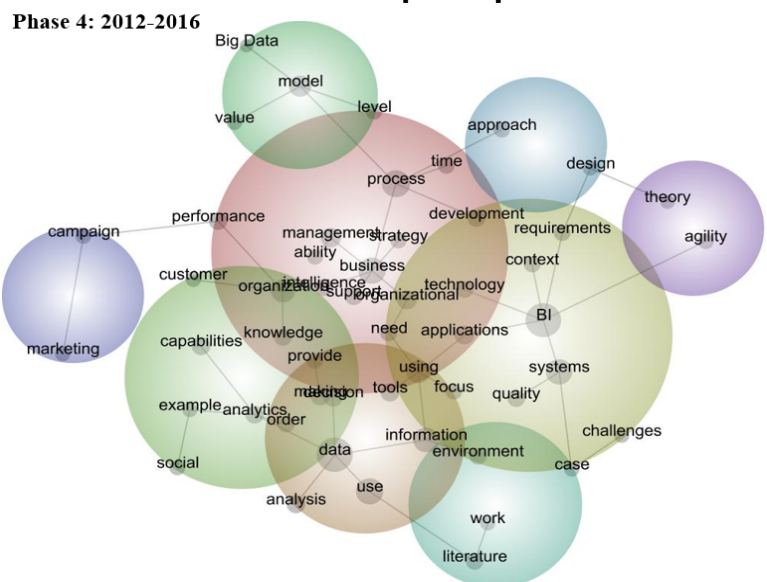

Figure 5. Leximancer concept map for Phase 4

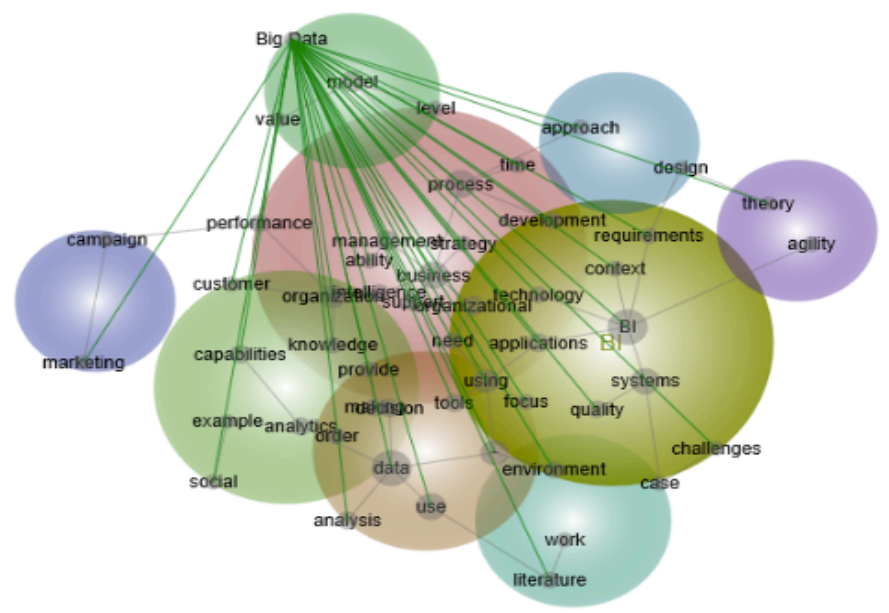

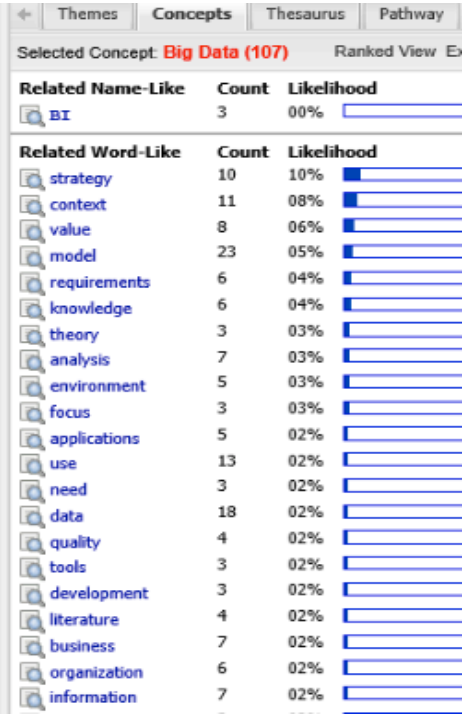

Figure 6. Leximancer analysis of the topic of 'Big data' 


\section{Discussion and future research}

Our study confirms that the 27-year history of this minitrack is fully aligned with the history of the BI\&A field (cf. Section 2) and often at the forefront of new research trends and developments. In addition to the text mining analysis we have checked the so-called Gartner BI\&A-related hype cycles from 2004 to 2015 (covering phase 3 and 4 of our analysis) since we consider them as suitable representatives for the practitioners' views of BI\&A topics and trends. Hype cycles provide a graphical representation of the maturity, adoption and business application of specific technologies. We are aiming at comparing the research topics presented in the minitrack and as identified by Leximancer in terms of concepts and themes with topics and trends as presented in the yearly hype cycles. While a detailed analysis is subject to further research we could already observe similar phases (also resulting in the renaming of titles, in this case of the hype cycles).

Table 4. Key concepts and themes observed across different phases

\begin{tabular}{|c|c|c|c|}
\hline $\begin{array}{l}\text { Minitrack } \\
\text { phase }\end{array}$ & $\begin{array}{l}\text { Key themes and } \\
\text { their relevance } \\
(10 \% \text { or above })\end{array}$ & $\begin{array}{l}\text { Key concepts } \\
\text { (an extract) }\end{array}$ & $\begin{array}{l}\text { Interpretation and further insights obtained from } \\
\text { more detailed analysis (drill-down) of the underlying } \\
\text { text }\end{array}$ \\
\hline 1990-1996 & $\begin{array}{l}\text { Information }(100 \%) \\
\text { EIS }(66 \%) \\
\text { System }(53 \%) \\
\text { Data }(50 \%) \\
\text { Problem }(18 \%), \\
\text { Approach }(14 \%) \\
\text { Knowledge }(10 \%) \\
\end{array}$ & $\begin{array}{l}\text { System } \\
\text { Use } \\
\text { Information } \\
\text { Executives } \\
\text { Management } \\
\text { Data }\end{array}$ & $\begin{array}{l}\text { The main emphasis is placed on EIS and their use by } \\
\text { executives and management. } \\
\text { A more detailed sentiment analysis of the experiences in } \\
\text { using these systems, as described in the papers, confirms } \\
\text { that these experiences were reported to be both positive } \\
\text { (i.e. favorable - 51\%) and negative (unfavorable - } 49 \% \text { ). }\end{array}$ \\
\hline $1997-2003$ & $\begin{array}{l}\text { Data }(100 \%) \\
\text { Distributed }(94 \%) \\
\text { System }(82 \%) \\
\text { User }(71 \%) \\
\text { Information }(41 \%) \\
\text { Metadata }(20 \%) \\
\text { Analysis }(15 \%) \\
\text { Case }(14 \%) \\
\text { Metrics }(13 \%)\end{array}$ & $\begin{array}{l}\text { Data } \\
\text { System } \\
\text { User } \\
\text { Database } \\
\text { Warehouse } \\
\text { Support } \\
\text { Query }\end{array}$ & $\begin{array}{l}\text { Consistent with the new name of this minitrack, the main } \\
\text { emphasis is placed on data, followed by systems. } \\
\text { Prominent concepts such as 'Database' and 'Query' } \\
\text { indicate a very strong focus on data storage and } \\
\text { processing. Further investigation of the concept } \\
\text { 'Warehouse' confirms that it is used to indicate 'data } \\
\text { warehouse' and to distinguish it from a more generic } \\
\text { concept of 'data'. } \\
\text { This group of papers also offers a number of case studies } \\
\text { as indicated by the key theme 'Case'. }\end{array}$ \\
\hline $2004-2011$ & $\begin{array}{l}\text { Information }(100 \%) \\
\text { Data }(73 \%) \\
\text { Value }(25 \%) \\
\text { Quality }(24 \%) \\
\text { Knowledge }(19 \%) \\
\text { Dimension }(15 \%)\end{array}$ & $\begin{array}{l}\text { Data } \\
\text { Used } \\
\text { Information } \\
\text { Business } \\
\text { Process } \\
\text { System }\end{array}$ & $\begin{array}{l}\text { This phase indicates a very visible shift from databases } \\
\text { and data warehouses to information (including the } \\
\text { challenges of turning data into information). The themes } \\
\text { of 'Value" and 'Knowledge' indicate challenges of } \\
\text { deriving business value of BI technology and turning } \\
\text { insights into knowledge. This phase also include papers on } \\
\text { conceptual modeling (as indicated by the theme } \\
\text { 'Dimension') and data quality. }\end{array}$ \\
\hline $2012-2016$ & $\begin{array}{l}\text { Process }(100 \%) \\
\text { Data }(93 \%) \\
\text { BI }(72 \%) \\
\text { Capabilities }(36 \%) \\
\text { Model }(16 \%) \\
\text { Literature }(16 \%)\end{array}$ & $\begin{array}{l}\text { Data } \\
\text { Use } \\
\text { Process } \\
\text { Systems } \\
\text { Information } \\
\text { Model } \\
\text { Business } \\
\text { Management }\end{array}$ & $\begin{array}{l}\text { The most prominent theme of 'process' includes business } \\
\text { processes, as well as other processes involved in the } \\
\text { organizational implementation of BI and BA. } \\
\text { In spite of the minitrack title now including 'big data', this } \\
\text { concept does not appear among the key concepts and } \\
\text { themes. BI is still a very prominent theme. However, our } \\
\text { analysis of the underlying paragraphs of text indicates } \\
\text { different interpretations of this term by researchers (e.g. } \\
\text { technology, analytics, an 'umbrella term'). It is also } \\
\text { interesting to observe a relatively strong emphasis on the } \\
\text { literature review papers. This is different from Phase } 2 \\
\text { where papers included more case studies. }\end{array}$ \\
\hline
\end{tabular}


While many researchers will continue to provide very valuable insights from their own literature reviews in this highly dynamic field, our method of using Leximancer to identify semantic relationships of the key concepts at the micro-level provides a complementary contribution of a different kind. By using this particular method, we extend the examination of the BI\&A literature beyond the morewidely used thematic analysis, systematic literature reviews and citation analysis. In practical terms we provide a demonstration of this method so that other researchers can replicate it in their own contexts.

Due to its versatile applications by other researchers, Leximancer has been described as a "textmining tool for visualizing the structure of concepts and themes in text" [2:25], a visual tool for making sense of big data [3], a data mining tool [36], a tool for qualitative data analysis [11], quantitative content analysis [28] and a quantitative tool for conducting qualitative analysis of text data [21].

Based on our experience in this project, we see our application of Leximancer, as a computer-supported qualitative study, with the overall process of sensemaking best described as iterative, reflective and human-driven, with meaning gradually emerging. This particular view challenges the assumption of "meaning" being automatically derived by any textmining tool, including Leximancer.

Consequently and in reflection, our research method could be described as a form of a technologysupported but human-driven sequence of hermeneutic circles [12], [14], [26]. This is because our understanding was constantly moving from the "whole" (the minitrack history and its phases), to the "parts" (thematic visualizations and corresponding raw text) and back to the whole. While the technology makes the text-mining process replicable and scalable, in our view it is human interpretation, by domain experts, that makes the results meaningful in a particular context.

Our method of using Leximancer provides future research opportunities, especially in relation to the emerging research topics such as big data. For example, it would be interesting to analyze the content of all big data-related papers published across different minitracks at this conference, as well as by other prominent IS conferences. This could provide researchers with additional insights into the focus and 'flavor' of a particular conference or minitrack so they could make important decisions where to send their work in the future.

\section{Conclusion}

Our research project reported in this paper has been inspired by the occasion of the 50th anniversary of the Hawaii International Conference on Systems Science (HICSS). As the current co-chairs of HICSS's longest running minitrack on $\mathrm{BI}, \mathrm{BA}$ and big data (as it is currently known), we report on its 27-year history of relevant and interesting research. We also demonstrate a method of using an advanced BI\&A tool for semantic text mining, as an illustration of our own "tool of the trade" applied within our own research context. In practical terms, other researchers, beyond BI\&A, could replicate the same method.

While comprehensive reviews of BI\&A and big data literature have been conducted elsewhere and are expected to continue, we focus on a single conference minitrack and analyze different phases of its history. Our analysis confirms that the minitrack's evolving progress from EIS, DW, BI, BA and most recently big data is fully aligned with industry trends. This alignment is very important, yet never easy to achieve, given the very dynamic nature of the BI\&A field and the ongoing challenges it continues to create for the researchers as well as academic conferences in terms of the required reviews and publication cycles. Our research also confirms the truly international nature of this minitrack that grew from its USA-based origins to now include papers from Europe, Australia, Asia/Pacific, Africa and USA. Our future work will include citation and social network analysis of minitrack contributions, research collaborations and the collective influence we continue to make.

The more recent history of HICSS has seen the introduction of other minitracks related to BI\&A (as defined in our paper), in particular those related to big data. Therefore, our data set remains limited to only one minitrack and should not be taken as representative of all BI\&A-related papers published by HICSS. However, being the longest running BI\&A-related minitrack at this conference, it has certainly contributed to HICSS being identified as the leading international conference for BI\&A-related research [9].

Finally, as the current custodians of the HICSS-50 minitrack "Organizational Issues of Business Intelligence, Business Analytics and Big Data", we acknowledge and thank all previous co-chairs, authors and reviewers who contributed to the 27-year long history of this minitrack. Together, we have contributed the total of 140 fully refereed research publications that will continue to shape the BI\&A for many years to come. We also thank the HICSS conference and track co-chairs (current and past) for their ongoing support and vision for this minitrack. 


\section{References}

[1] Abbasi, A., Sarker, S., and Chiang, R.H.L. Big data research in information systems: Toward an inclusive research agenda. Journal of the Association of Information Systems 17, 2 (2016), pp. 1-32.

[2] Anagnostopoulos, C. and Bason, T. Mapping the First 10 Years with Leximancer: Themes and Concepts in the Sports Management. International Journal Choregia 11, 1 (2015), pp. $25-41$.

[3] Angus, D., Rintel, S., and Wiles, J. Making sense of big text: a visual-first approach for analysing text data using Leximancer and Discursis. International Journal of Social Research Methodology 16, 3 (2013), pp. 261-267.

[4] Arnott, D. and Pervan, G. A critical analysis of decision support systems research. Journal of Information Technology 20, 2 (2005), pp. 67-87.

[5] Aryal, A., Gallivan, M., and Tao, Y. Using Latent Semantic Analysis to Identify Themes in IS Healthcare Research. Proceedings of the 21th Americas Conference on Information Systems (AMCIS'2015), (2015), pp. 1-7.

[6] Baars, H., Felden, C., Gluchowski, P., Hilbert, A., Kemper, H.G., and Olbrich, S. Shaping the next incarnation of Business intelligence: Towards a flexibly governed network of information integration and analysis capabilities. Business and Information Systems Engineering 6, 1 (2014), pp. 11-16.

[7] Carter, M., Petter, S., and Randolph, A.B. Desperately seeking information in information systems research. Proceedings of the 36th Conference on Information Systems (ICIS'2015), (2015), pp. 1-9.

[8] Chee, T., Chan, L.-K., Chuah, M.-H., Tan, C.-S., Wong, S.-F., and Yeoh, W. Business Intelligence Systems: State-ofthe-Art Review and Contemporary Applications. Symposium on Progress in Information and Communication Technology (SPICT’09), (2009), pp. 96-101.

[9] Chen, H., Chiang, R.H.L., and Storey, V.C. Business Intelligence and Analytics: From Big Data To Big Impact. MIS Quarterly 36, 4 (2012), pp. 1165-1188.

[10] Cretchley, J., Rooney, D., and Gallois, C. Mapping a 40Year History With Leximancer: Themes and Concepts in the Journal of Cross-Cultural Psychology. Journal of CrossCultural Psychology 41, 3 (2010), pp. 318-328.

[11] Crofts, K. and Bisman, J. Interrogating accountability: An illustration of the use of Leximancer software for qualitative data analysis. Qualitative Research in Accounting and Management 7, 2 (2010), pp. 180-207.

[12] Crotty, M. The Foundations of Social Research: Meaning and Perspective in the Research Process. Allen \& Unwin, St. Leonards, (1998).
[13] Cuzzocrea, A., Saccà, D., and Ullman, J.D. Big data: A research agenda. Proceedings of the 17th International Database Engineering \& Applications Symposium (IDEAS '13), (2013),pp. 198-203.

[14] Gadamer, H.-G. Truth and Method. Continuum, New York, 1960.

[15] Gartner. Gartner Executive Program Survey of more than 2000 CIOs shows Digital Technologies are top priorities in 2013. 2013, [Available at: http://www.gartner.com/newsroom/id/2304615].

[16] Gopalkrishnan, V. and Steier, D. Big data, big business: bridging the gap. Proceedings of the 1st International Workshop on Big Data, Streams and Heterogeneous Source Mining (BigMine'12), (2012), pp. 7-11.

[17] Goul, M. Business intelligence at the crossroads: Convergence or confusion ahead? Proceedings of the International Conference on Information Technology Interfaces (ITI'13), (2010), pp. 21-28.

[18] Gupta, B., Goul, M., and Dinter, B. Business intelligence and big data in higher education: Status of a multi-year model curriculum development effort for business school undergraduates, MS graduates, and MBAs. Communications of the Association for Information Systems 36, 1 (2015), pp. 449-476.

[19] Hashem, I.A.T., Yaqoob, I., Badrul Anuar, N., Mokhtar, S., Gani, A., and Ullah Khan, S. The rise of "Big Data" on cloud computing: Review and open research issues. Information Systems 47, (2015), pp. 98-115.

[20] Hosack, B., Hall, D., Paradice, D., and Courtney, J.F. A Look Toward the Future: Decision Support Systems Research is Alive and Well. Journal of the Association for Information Systems 13, 5 (2012), pp. 315-340.

[21] Indulska, M., Hovorka, D.S., and Recker, J. Quantitative approaches to content analysis: identifying conceptual drift across publication outlets. European Journal of Information Systems 21, 1 (2012), pp. 49-69.

[22] Indulska, M. and Recker, J.C. Design Science in IS Research: A Literature Analysis. In G. Shirley and S. Ho, eds., Proceedings of the 4th Biennial ANU Workshop on Information Systems Foundations. Canberra, Australia, 2008, pp. 1-13.

[23] Jin, X., Wah, B.W., Cheng, X., and Wang, Y. Significance and Challenges of Big Data Research. Big Data Research 2, 2 (2015), pp. 59-64.

[24] Jourdan, Z., Kelly Rainer, R., and Marshall, T.E. Business Intelligence: An Analysis of the Literature. Information Systems Management 25, 2 (2008), pp. 121131. 
[25] Kambatla, K., Kollias, G., Kumar, V., and Grama, A. Trends in big data analytics. Journal of Parallel and Distributed Computing 74, 7 (2014), pp. 2561-2573.

[26] Klein, H.K. and Myers, M.D. A set of principles for conducting and evaluating interpretive field studies in information systems. MIS Quarterly 23, 1 (1999), pp. 67-94.

[27] Leximancer. White Paper. Brisbane Australia, 2010, [Available at: https://www.leximancer.com/lmedia/Leximancer_White_Pap er_2010.pdf].

[28] Lock, I. and Seele, P. Quantitative content analysis as a method for business ethics research. Business Ethics: A European Review 24, S1 (2015), pp. S24-S40.

[29] Luftman, J., Zadeh, H.S., Derksen, B., et.al.. Key information technology and management issues 2012-2013: An international study. Journal of Information Technology 28, 4 (2013), pp. 354-366.

[30] Negash, S. Business intelligence. Communications of the Association for Information Systems 13, 1 (2004), pp. 177-195.

[31] Philip Chen, C.L. and Zhang, C.Y. Data-intensive applications, challenges, techniques and technologies: A survey on Big Data. Information Sciences 275, 2014 (2014), pp. 314-347.

[32] Phillips-Wren, G., Iyer, L.S., Kulkarni, U., and Ariyachandra, T. Business analytics in the context of big data: A roadmap for research. Communications of the Association for Information Systems 37, 1 (2015), pp. 448472.
[33] Power, D.J. A brief history of Decision Support Systems. DSSResources.com. March 10. (2007), pp.1-17.

[34] Pirttimäki, V.H. Conceptual analysis of business intelligence. South African Journal of Information Management 9, 2 (2007).

[35] Shollo, A. and Kautz, K. Towards an Understanding of Business Intelligence. 21st Australasian Conference on Information Systems (ACIS'2010), (2010), Paper 86.

[36] Smith, A.E. and Humphreys, M.S. Evaluation of unsupervised semantic mapping of natural language with Leximancer concept mapping. Behavior Research Methods 38, 2 (2006), pp. 262-279.

[37] Watson, H.J. Tutorial: Business intelligence - Past, present, and future. Communications of the Association for Information Systems 25, 1 (2009), pp. 487-510.

[38] Watson, H.J. Tutorial: Big Data Analytics: Concepts, Technologies, and Applications. Communications of the Association for Information Systems 34, 1 (2014), pp. 12471268 .

[39] Young, L., Wilkinson, I., and Smith, A. A Scientometric Analysis of Publications in the Journal of Business-toBusiness Marketing 1993-2014. Journal of Business-toBusiness Marketing 22, 1-2 (2015), pp. 111-123. 